\title{
Large variation in effects during 10 years of enzyme therapy in adults with Pompe disease
}

Laurike Harlaar, MD, Jean-Yves Hogrel, PhD, Barbara Perniconi, CRA, Michelle E. Kruijshaar, PhD, Dimitris Rizopoulos, PhD, Nadjib Taouagh, CRA, Aurélie Canal, PT, Esther Brusse, MD, PhD, Pieter A. van Doorn, MD, PhD, Ans T. van der Ploeg, MD, PhD, Pascal Laforêt, MD, PhD, ${ }^{*}$ and Nadine A. M. E. van der Beek, MD, PhD*

Neurology ${ }^{\circledR}$ 2019;93:e1756-e1767. doi:10.1212/WNL.0000000000008441

\section{Abstract}

\section{Objective}

To determine the effects of 10 years of enzyme replacement therapy (ERT) in adult patients with Pompe disease, focusing on individual variability in treatment response.

\section{Methods}

In this prospective, multicenter cohort study, we studied 30 patients from the Netherlands and France who had started ERT during the only randomized placebo-controlled clinical trial with ERT in late-onset Pompe disease (NCT00158600) or its extension (NCT00455195) in 2005 to 2008. Main outcomes were walking ability (6-minute walk test [6MWT]), muscle strength (manual muscle testing using Medical Research Council [MRC] grading), and pulmonary function (forced vital capacity [FVC] in the upright and supine positions), assessed at 3- to 6-month intervals before and after the start of ERT. Data were analyzed with linear mixedeffects models for repeated measurements.

\section{Results}

Median follow-up duration on ERT was 9.8 years (interquartile range [IQR] 8.3-10.2 years). At the group level, baseline $6 \mathrm{MWT}$ was $49 \%$ of predicted (IQR $41 \%-60 \%$ ) and had deteriorated by 22.2 percentage points $(\mathrm{pp})$ at the 10 -year treatment point $(p<0.001)$. Baseline FVC upright was 54\% of predicted (IQR 47\%-68\%) and decreased by 11 pp over 10 years $(p<$ 0.001). Effects of ERT on MRC sum score and FVC supine were similar. At the individual level, $93 \%$ of patients had initial benefit of ERT. Depending on the outcome measured, $35 \%$ to $63 \%$ of patients had a secondary decline after $\approx 3$ to 5 years. Still, at 10 years of ERT, $52 \%$ had equal or better $6 \mathrm{MWT}$ and/or FVC upright compared to baseline.

\section{Conclusions}

The majority of patients with Pompe disease benefit from long-term ERT, but many patients experience some secondary decline after $\approx 3$ to 5 years. Individual variation, however, is considerable.

\section{Classification of evidence}

This study provides Class IV evidence that for the majority of adults with Pompe disease, longterm ERT positively affects, or slows deterioration in, muscle strength, walking ability, and/or pulmonary function.

\author{
Correspondence \\ Dr. van der Beek \\ n.beek@erasmusmc.nl
}

\section{MORE ONLINE}

$\rightarrow$ Class of Evidence

Criteria for rating

therapeutic and diagnostic studies

NPub.org/coe

\section{Q CME Course}

NPub.org/cmelist

\footnotetext{
*These authors contributed equally to this work.

From the Departments of Neurology (L.H., E.B., P.A.v.D., N.A.M.E.v.d.B.) and Pediatrics (M.E.K., A.T.v.d.P.), Center for Lysosomal and Metabolic Diseases Erasmus MC, and Department of Biostatistics (D.R.), University Medical Center Rotterdam, Netherlands; Institute of Myology (J.-Y.H., B.P., N.T., A.C.), Pitié-Salpêtrière Hospital, Paris; Department of Neurology (P.L.), Nord/Est/lle de France Neuromuscular Center, Raymond Poincaré Teaching Hospital, AP-HP, Garches; and INSERM U1179 (P.L.), END-ICAP, Université Versailles SaintQuentin-en-Yvelines, Montigny-le-Bretonneux, France.

Go to Neurology.org/N for full disclosures. Funding information and disclosures deemed relevant by the authors, if any, are provided at the end of the article. 


\section{Glossary}

ERT = enzyme replacement therapy; FVC = forced vital capacity; IQR = interquartile range; LOTS = Late-Onset Treatment Study; MEP = maximal expiratory pressure; $\mathbf{M I P}=$ maximal inspiratory pressure; $\mathbf{M R C}=$ Medical Research Council; $\mathbf{M 6 P}=$ mannose-6-phosphate; pp = percentage points; $\mathrm{QMT}=$ quantitative muscle testing; $6 \mathrm{MWT}=6$-minute walk test.

Enzyme replacement therapy (ERT) with recombinant human acid $\alpha$-glucosidase (alglucosidase alfa, myozyme) has become the standard of care in the treatment of patients with Pompe disease, a relentlessly progressive, autosomal recessive myopathy caused by a deficiency of acid $\alpha$-glucosidase. ${ }^{1,2}$ The disease may manifest at any age, from infancy to late adulthood, and the type and severity of symptoms vary widely. Skeletal muscle weakness and respiratory dysfunction are the hallmarks of the phenotype in adults. ${ }^{3,4}$ Ultimately, without treatment, the majority of adult patients become dependent on the use of a wheelchair and/or mechanical ventilatory support, leading to severe limitations in daily living.

Several longitudinal studies up to a median of 5 years of ERT treatment showed that treated patients had improved ambulatory function and muscle strength, stabilization of pulmonary function, and increased survival. ${ }^{5-10}$ However, recent studies show that the effect of ERT seems to peak at 2 to 3 years of treatment and is followed by a plateau or secondary decline. Because no studies with follow-up $>5$ years are available, it is unknown if this plateau is maintained or whether a further, more rapid, decline follows. Furthermore, several studies have reported substantial individual differences in treatment benefit. ${ }^{6,8,9} \mathrm{~A}$ better understanding of such differences could help to predict individual treatment response and to guide decisions about starting and stopping ERT.

We had the unique opportunity to study 30 patients from the Netherlands and France who had participated in the only randomized placebo-controlled clinical trial with ERT in lateonset Pompe disease ${ }^{11,12}$ who have now been carefully followed up for 10 years. We investigated the effects of ERT on muscle strength, walking ability, and pulmonary function and delineated individual patients' treatment response.

\section{Methods}

\section{Study design and participants}

This study was a prospective, open-label cohort study involving 30 patients with a confirmed diagnosis of Pompe disease. It is being conducted at the Center for Lysosomal and Metabolic Diseases, Erasmus MC University Medical Center, Rotterdam $(\mathrm{n}=20)$, and the Institute of Myology, PitiéSalpêtrière Hospital, Paris $(\mathrm{n}=10)$, both nationally endorsed centers of expertise in Pompe disease. From 2005 to 2007, all patients had participated in the randomized, double-blind, placebo-controlled study on the effects of enzyme therapy in patients with late-onset Pompe (Late-Onset Treatment
Study [LOTS], NCT00158600), ${ }^{11}$ in which patients were randomized in a 2:1 ratio to receive biweekly IV infusions of $20 \mathrm{mg} / \mathrm{kg}$ alglucosidase alfa or placebo for up to 78 weeks. Eligibility criteria for that study included (1) evidence of lower extremity muscle weakness while still being able to walk $40 \mathrm{~m}$ on the 6-minute walk test (6MWT); (2) an upright seated forced vital capacity (FVC) percent predicted between $30 \%$ and $80 \%$; (3) a drop in FVC of $\geq 10 \%$ when changing from the upright to the supine position; (4) no invasive ventilation; and (5) no noninvasive ventilation while awake and upright. In the subsequent open-label extension study (NCT00455195), all patients received alglucosidase alfa for another 26 weeks. ${ }^{12}$ ERT was continued thereafter unless patients experienced unmanageable adverse reactions or decided to stop treatment. Clinical assessments took place every 3 to 6 months before and after the start of ERT. The earliest measurements before the start of ERT that were used to assess the disease course of untreated patients are from 1991. For this study, database lock was July 1, 2016.

\section{Procedures}

\section{Walking ability and muscle strength}

We used the 6MWT as a test of functional endurance. Values are presented as a percentage of predicted normal values to account for the effects of age, height, weight, and sex. ${ }^{13}$

In addition, skeletal muscle strength was measured by manual muscle testing with the Medical Research Council (MRC) grading scale ${ }^{14}$ or the modified MRC scale. ${ }^{15}$ For the purpose of the current analyses, only full grades $(0-5)$ were used. The following muscle groups were tested to calculate an MRC sum score (range 0-95): neck flexors, bilateral shoulder abductors, elbow flexors, elbow extensors, hip flexors, hip extensors, hip abductors, hip adductors, knee flexors, and knee extensors. This score was subsequently converted to a percentage of the maximum possible score. As an additional outcome of muscle strength, we used the quantitative measurement system (quantitative muscle testing [QMT]) of the Cooperative International Neuromuscular Research Group (maximal voluntary isometric contraction) to calculate a composite QMT leg score. ${ }^{11,16,17}$

\section{Pulmonary function}

FVC was measured with the patient in an upright seated and a supine position. Furthermore, maximal inspiratory (MIP) and maximal expiratory (MEP) mouth pressures were measured in the upright seated position. All measurements were performed according to standards of the American Thoracic Society/European Respiratory Society. ${ }^{18,19}$ 
Results were expressed as a percentage of the predicted normal value. ${ }^{20,21}$

\section{Additional clinical information}

Information was gathered on the following: (1) sex; (2) height; (3) weight; (4) age at symptom onset; (5) age at the start of ERT, (6) use of a wheelchair; (7) use of mechanical ventilatory support; (8) genotype; and (9) peak titers of antibodies against alglucosidase alfa during the first 3 years of ERT. $^{11,22,23}$

\section{Statistical analyses}

\section{Group level}

Longitudinal analyses of 6MWT, MRC sum score, QMT leg score, FVC upright, FVC supine, MIP, and MEP were performed with linear mixed models to account for correlations in the repeated measurements per patient, as reported previously. ${ }^{8}$ The current analyses include between 503 and 604 measurements per outcome measure. Measurements performed after cessation of ERT treatment were excluded. We report the outcomes at 10 years of treatment compared to baseline. To correct for possible differences between the patients at the start of ERT and how these may affect the longitudinal profiles of the outcome, we included interactions of the nonlinear time effect with sex, disease duration at the start of ERT ( $\leq 17$ or $>17$ years; calculated from onset of first symptoms), FVC upright at the start of ERT $(\leq 55 \%$ or $>55 \%$ predicted), and $6 \mathrm{MWT}$ at the start of ERT $(\leq 50 \%$ or $>50 \%$ predicted) in the models. Cutoff points are based on median values of the total group. These interactions were retained if they were found to improve the fit of the model. The assumptions of the models were checked with residual plots.

For FVC, sufficient data on the disease course before start of ERT (i.e., natural disease course) were available to compare patients' outcomes under treatment with their situation without treatment. To this end, we extrapolated patients' natural course data, assuming linear evolutions over time, 8,24 and compared these to the observed values at the 10-year treatment point. We used all data until the time point at which $95 \%$ of data were available to avoid influence of individual patients with longer follow-up.

Overall treatment effects were tested with likelihood ratio tests. Differences were expressed in absolute percentage points (pp). The significance level was set at 0.05 .

\section{Individual level}

For 6MWT, MRC sum score, QMT leg score, FVC upright, and FVC supine, we assessed patients' individual response to ERT until cessation of treatment or end of follow-up, respective to their situation at the start of ERT. Per outcome, each patients' course during ERT was visualized in scatterplots. Subsequently, 5 independent observers (clinicians involved in the care for patients with Pompe disease) blinded for the patient's identification classified their response into 8 groups: (1) improvement throughout the study; (2) initial improvement followed by stabilization; (3) initial improvement followed by decline; (4) stable throughout the study; (5) initial stabilization followed by decline; (6) decline throughout the study; (7) initial decline followed by stabilization or improvement; and (8) unclassifiable. Examples of the various response patterns are shown in figure 1. Consensus was reached when at least 4 of the observers agreed on the response pattern. If no consensus had been reached, results were discussed in a separate meeting (L.H., J.-Y.H., N.A.M.E.v.d.B.). For more intuitional interpretation of the overall results, initial improvement or stabilization with regard to a patient's baseline measurement was classified as a positive response, even if followed by a secondary decline later during follow-up (figure 1, patterns 1 through 5), while deterioration despite ERT was regarded as a negative outcome (figure 1, pattern 6).

In addition, we assessed patients' individual response to ERT respective to the start of treatment. Their response was classified into 3 groups: improvement ( $>2$ pp above baseline level), stabilization (between -2 and +2 pp from baseline level), and deterioration ( $>2 \mathrm{pp}$ below baseline level).

Analyses were performed with SPSS for Windows (version 24, SPSS Inc, Chicago, IL) and R version 3.2.2 (2015-08-14, R Foundation for Statistical Computing, Vienna, Austria) using the nlme package (version 3.1-121).

\section{Standard protocol approvals, registrations, and patient consents}

The study protocols were approved by the Medical Ethical Committees of Erasmus MC University Medical Center or Pitié-Salpêtrière Hospital. All patients gave their written informed consent.

\section{Classification of evidence}

This study provides Class IV evidence that for the majority of adults with Pompe disease, long-term ERT positively affects, or slows deterioration in, muscle strength, walking ability, and/or pulmonary function.

\section{Data availability}

Anonymized data will be shared by request from any qualified investigator for the sole purpose of replicating procedures and results presented in the article and as long as data transfer is in agreement with European Union legislation on the general data protection regulation.

\section{Results}

\section{Patients}

Thirty patients (the Netherlands $n=20$, France $n=10$ ) participated in this study (table). There were no differences in age, disease duration, or disease severity at the start of ERT 
A. Improvement throughout study
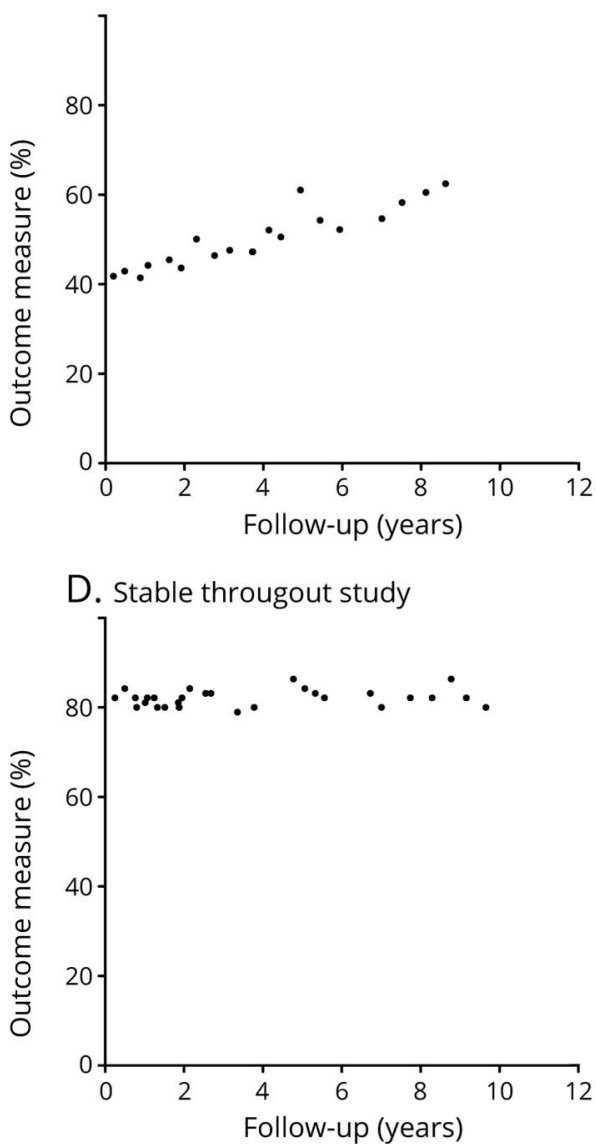

F. Decline throughout study

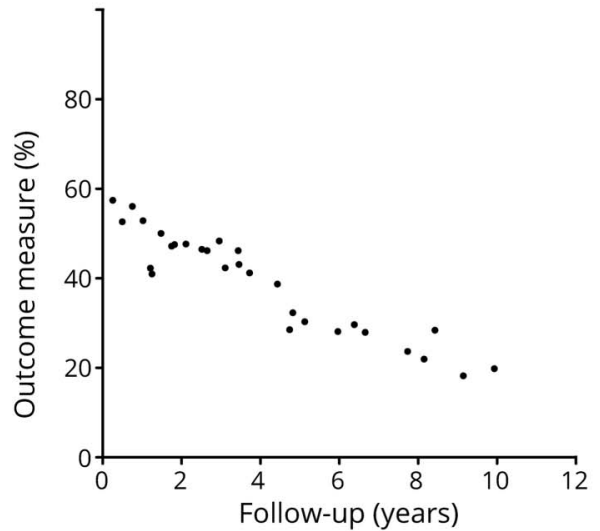

B. Initial improvement followed by stabilization

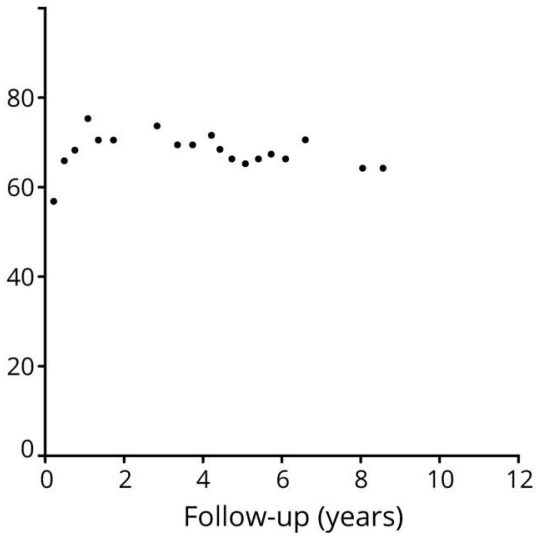

E. Initial stabilization followed by decline

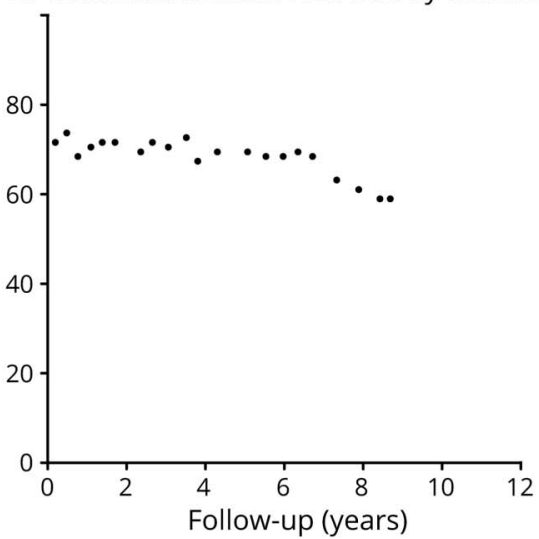

G. Initial decline followed by stablization or improvement

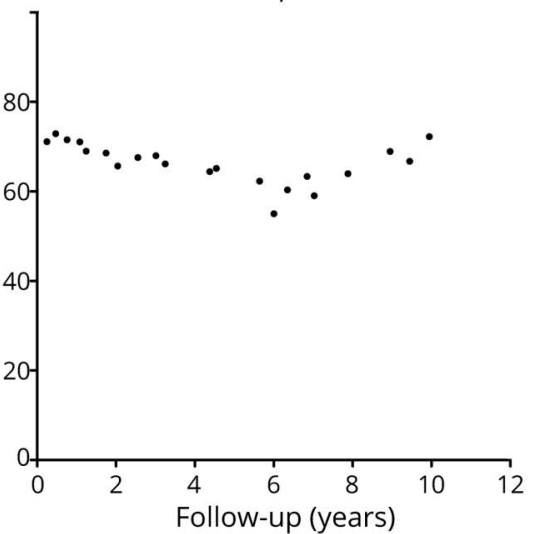

C. Initial improvement followed by decline

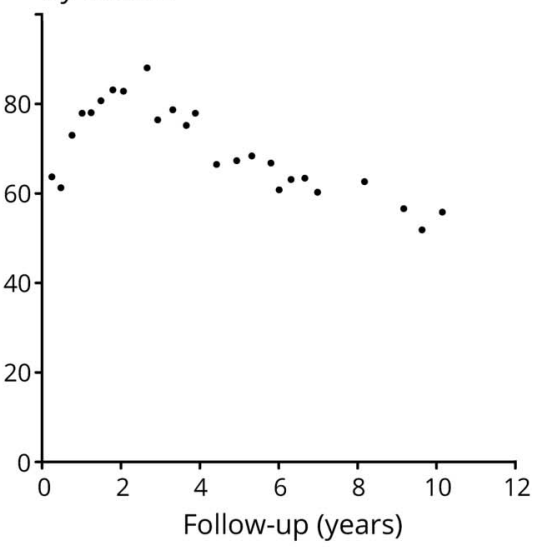


Table Patients' characteristics

\begin{tabular}{|c|c|c|}
\hline \multicolumn{2}{|l|}{ Patients, $\mathbf{n}$ (\% of total) } & $30(100)$ \\
\hline \multicolumn{2}{|l|}{ Male } & $14(47)$ \\
\hline \multicolumn{2}{|l|}{ Female } & $16(53)$ \\
\hline \multicolumn{3}{|l|}{ Genotype, $n$ ( $\%$ of total) $(n=30)$} \\
\hline \multicolumn{2}{|l|}{ c.-32-13T>G/c.525delT } & $9(30)$ \\
\hline \multicolumn{2}{|l|}{ c.-32-13T>G/other disease-causing variant ${ }^{a}$} & $19(63)$ \\
\hline \multicolumn{2}{|l|}{ c.1748C $>T / c .2014 C>T$} & $2(7)$ \\
\hline \multicolumn{3}{|c|}{ Peak titers of antibodies against alglucosidase alfa, ${ }^{b}(\%$ of total) $(n=30)$} \\
\hline \multicolumn{2}{|l|}{ Low $(0-<1: 1,250)$} & $4(13)$ \\
\hline \multicolumn{2}{|l|}{ Intermediate $(1: 1,250-<1: 31,250)$} & $16(53)$ \\
\hline \multicolumn{2}{|l|}{ High $(\geq 1: 31,250)$} & $9(30)$ \\
\hline \multicolumn{2}{|l|}{ Not available } & $1(3)$ \\
\hline \multicolumn{2}{|l|}{ Patients stopped ERT, $n$ (\% of total) $(n=30)$} & $3(10)$ \\
\hline \multicolumn{2}{|c|}{ Patients died during treatment with ERT, $n(\%$ of total) $(n=30)$} & $1(3)$ \\
\hline \multicolumn{2}{|l|}{ Follow-up duration on ERT, median (IQR), y } & $9.8(8.3-10.2)$ \\
\hline \multicolumn{3}{|l|}{ Baseline characteristics at start of ERT, median (IQR) } \\
\hline \multicolumn{2}{|l|}{ Age, y } & $49(41-60)$ \\
\hline \multicolumn{2}{|l|}{ Disease duration from symptom onset, $y$} & $17(10-23)$ \\
\hline \multicolumn{2}{|l|}{ 6MWT, \%pred } & $49(41-62)$ \\
\hline \multicolumn{2}{|l|}{ MRC sum score, \%max } & $69(65-83)$ \\
\hline \multicolumn{2}{|l|}{ QMT leg score, \%pred } & $36(26-55)$ \\
\hline \multicolumn{2}{|l|}{ FVC upright, \%pred } & $54(47-68)$ \\
\hline \multicolumn{2}{|l|}{ FVC supine, \%pred } & $33(24-53)$ \\
\hline \multicolumn{2}{|l|}{ MIP, \%pred } & $49(39-64)$ \\
\hline \multicolumn{2}{|l|}{ MEP, \%pred } & $50(39-61)$ \\
\hline Assistive devices, $n$ (\% of total) $(n=30)$ & Start of ERT & End of follow-up \\
\hline Wheelchair & $7(23)$ & $13(43)$ \\
\hline Partially wheelchair dependent & $7(23)$ & $10(33)$ \\
\hline Fully wheelchair dependent (walking $<40 \mathrm{~m}$ ) & $0(0)$ & $3(10)^{c}$ \\
\hline Noninvasive ventilation & $7(23)$ & $24(80)^{c d}$ \\
\hline
\end{tabular}

Abbreviations: $E R T$ = enzyme replacement therapy; FVC = forced vital capacity; IQR = interquartile range; $\mathrm{MEP}=$ maximal expiratory pressure; $\mathrm{MIP}=$ maximal inspiratory pressure; MRC = Medical Research Council; QMT = quantitative muscle testing; 6MWT = 6-minute walk test; \%max =\% of maximum outcome; \% pred $=\%$ of predicted outcome.

${ }^{a}$ Other disease-causing variants on the second allele were c.379_380del $(n=1), c .-32-13 T>G(n=1), c .118 C>T(n=1), c .1373 \_1375 d e l(n=1)$, c.1396G $>T(n=1)$, $c .1548 G>A(n=2), c .1636+1 G>C(n=1), c .1717 A>C(n=1), c .172 C>T(n=1), c .1799 G>A(n=2), c .1888+1 G>A(n=1), c .2314 T>C(n=1), c .2608 C>T(n=1), c .461$. 469del $(n=1)$, c.2481+102_2646+31del $(n=2)$, and c.573C>A $(n=1)$.

${ }^{\mathrm{b}}$ Antibody titers were determined between 1 and 36 months after the start of ERT. The reported titers indicate the peak titers during this period. ${ }^{22}$

' One patient became fully wheelchair dependent and needed noninvasive ventilation after the cessation of ERT.

${ }^{\mathrm{d}}$ One patient used noninvasive ventilation because of obstructive sleep apnea syndrome.

During treatment, the walking distance improved during the first 3 years (figure $3 \mathrm{~A}$ ). After this period, we noticed a secondary decline; at the 10-year treatment point, the average 6MWT was lower than at the start of treatment $(-22.2 \mathrm{pp}$, $p<0.001)$. The course over time was independent of sex, disease duration ( $\leq 17$ or $>17$ years), and severity at the start of treatment (6MWT at the start of ERT $\leq 50 \%$ or $>50 \%$, FVC upright at the start of ERT $\leq 55 \%$ or $>55 \%$ ). 


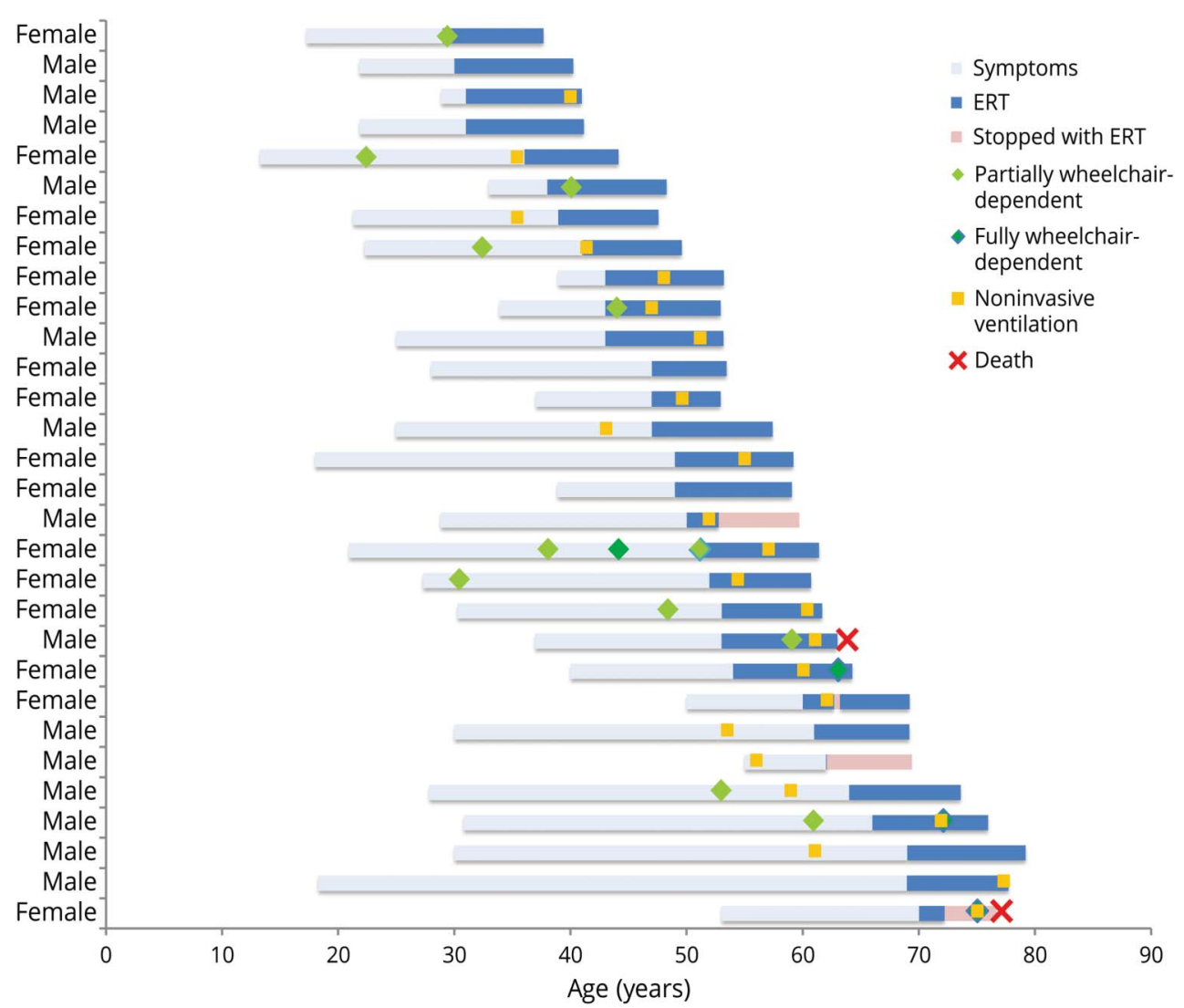

Each bar represents 1 individual patient. The length of each bar represents the symptom duration before the start of enzyme replacement therapy (ERT) (light blue), follow-up period during ERT (dark blue), and follow-up duration after stopping ERT (red). The age at the start of using a wheelchair (green diamond), ventilation (yellow square), or death (red cross) is indicated.
Two patients became fully wheelchair dependent during the treatment period (after 2.8 and 8.7 years of ERT), while another 6 patients were not able to perform the 6MWT anymore because of the high risk of falling. In total, 13 patients (43\%) were partially or fully wheelchair dependent at the end of follow-up compared to 7 patients (23\%) at the start of ERT.

Relative to the start of treatment, MRC sum score and QMT leg score were also lower after 10 years of ERT (figure 3, B and C). Response to ERT on the MRC sum score was influenced by sex and walking ability at the start of treatment. Men with a baseline walking ability $>50 \%$ did best $(-5.5 \mathrm{pp}, p=0.05)$, while women with a walking ability $\leq 50 \%$ had the greatest decline $(-10.5 \mathrm{pp}, p<0.001)$. The decline was $-6.8 \mathrm{pp}(p=$ $0.001)$ in men with $6 \mathrm{MWT} \leq 50 \%$ and $-9.2 \mathrm{pp}(p<0.001)$ in women with baseline 6MWT $>50 \%$. QMT leg score decreased by $-7.5 \mathrm{pp}$ after 10 years of treatment $(p=0.002)$.

\section{Pulmonary function}

At the start of ERT, median FVC in the upright position was $54 \%$ of predicted (IQR 47\%-68\%) and in the supine position was $33 \%$ of predicted (IQR 24\%-53\%) (table). Overall, FVC in the upright position was relatively stable over the first 5 years of treatment. However, after this period, a decline was observed (figure 4A). After 10 years of treatment, upright FVC had decreased by -11 pp $(p<0.001)$. FVC in supine position declined slowly in a linear way from the start of treatment (-9.2 pp at the 10-year time-point, $p<0.001$; figure 4B). MIP and MEP data showed a rather stable course over 10 years of treatment $(-1.8$ and $-2.5 \mathrm{pp}$ at the 10 -year timepoint, $p=\mathrm{NS}$; figure 4, C and D). Sex, disease duration, and baseline disease severity did not significantly alter the disease course on ERT.

Relative to the extrapolated natural course, patients had better pulmonary function parameters at 10 years of ERT (figure 4, $\mathrm{E}$ and F). Their FVC in the upright position was $13.2 \mathrm{pp}$ higher $(p<0.001)$, while their FVC in supine position was 8.5 pp higher $(p=N S)$.

During follow-up, between 4.8 and 9.1 years after the start of ERT, 5 patients were no longer able to perform the measurements in the supine position due to severe orthopnea or full wheelchair dependency. By study end, 24 patients (80\%) needed noninvasive ventilation compared to 7 patients (23\%) at the start of ERT.

\section{Individual response to ERT}

We analyzed the individual course during ERT for 29 patients. One patient received ERT for 1 month only due to severe infusion-associated reactions and was thus excluded from this specific analysis. 
Figure 3 Effect of ERT on walking ability and muscle strength

A

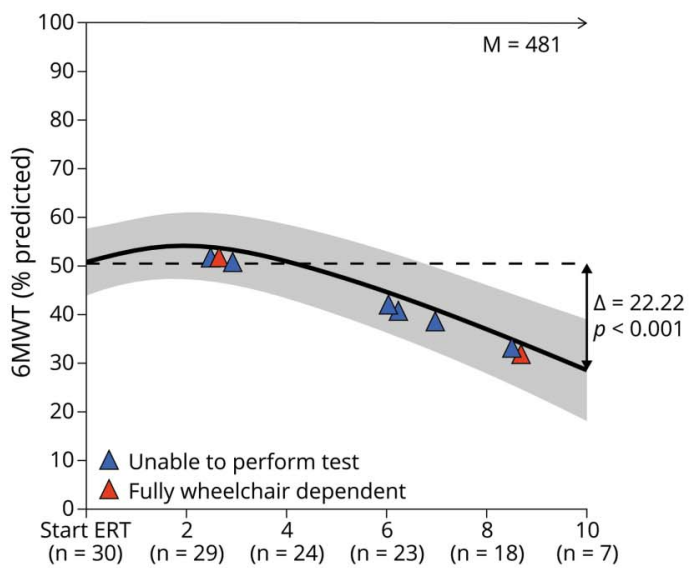

B

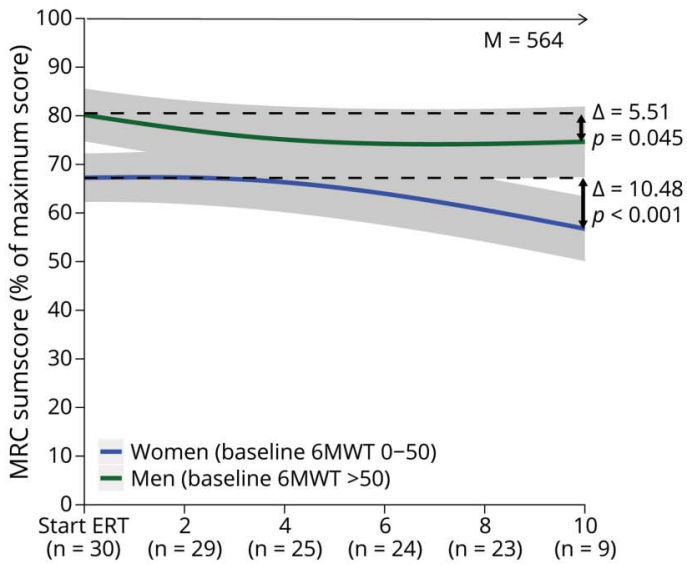

C

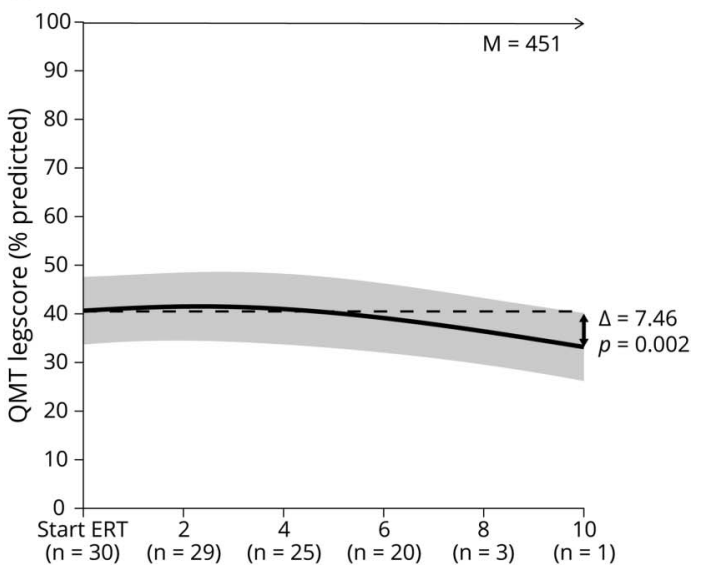

Follow-up duration in years (number of patients)

Disease course at the group level after the start of enzyme replacement therapy (ERT) for (A) 6-minute walk test (6MWT), (B) Medical Research Council (MRC) sum score, and (C) QMT leg score. Solid lines represent the measured course during treatment. The 95\% confidence intervals are shown in gray. For 6MWT, the triangles mark the time point from which individual patients were not able to perform the test due to the risk of falling (blue triangle) or full wheelchair dependency (red triangle). For MRC sum score, the disease courses of the best (men, baseline $6 \mathrm{MWT}>50 \%$ predicted) and worst (women, baseline $6 \mathrm{MWT} \leq 50 \%$ predicted) subgroups are shown. The other 2 subgroups (men, baseline 6MWT $\leq 50 \%$ predicted; women, baseline $6 \mathrm{MWT}>50 \%$ predicted) had an intermediate course. $\mathrm{M}=$ total number of measurements; $n=$ number of patients at that time of follow-up.
As an initial response, 24 patients (83\%) showed stabilization or improvement in their distance walked in 6 minutes compared with the start of ERT, interpreted as a positive response. For the other outcomes, we saw similar patterns: for MRC sum score, 17 patients (59\%) had an initial positive response to ERT; for QMT leg score, 22 patients (76\%); for FVC upright, 20 patients (69\%); and for FVC supine, 19 patients (66\%) (figure 5).

A substantial number of patients had a secondary deterioration after an initial positive response to ERT (6MWT, $\mathrm{n}=15$ of 24 [63\%]; MRC sum score, $\mathrm{n}=6$ of 17 [35\%]; QMT leg score, $\mathrm{n}=6$ of 22 [27\%]; FVC upright, $\mathrm{n}=11$ of 20 [55\%]; FVC supine, $n=9$ of $19[47 \%])$. The time point of this change in disease course differed for individual patients; some patients had a change in course after the first 1 to 2 years of treatment, while other patients seemed to respond well up to 7 to 8 years of treatment.

Notably, for FVC in the upright position, 3 patients (10\%) showed an initial decline followed by a secondary stabilization. This stabilization coincided with the start of noninvasive mechanical ventilation.

Relative to the start of ERT, at their last follow-up measurement, $34 \%$ of patients had better or similar 6MWT distance, $17 \%$ had better or similar MRC sum score, and $31 \%$ had better or similar FVC in the upright or supine position (figure 5).

A combined analysis for effect of ERT on 6MWT and upright FVC, which were coprimary endpoints in the LOTS study, showed that 27 patients (93\%) had at least a positive response to ERT in 6MWT and/or FVC upright for several years (figure 5B). Five of these patients $(17 \%$ of all patients) had a very good response to ERT, having similar or better scores in both outcomes during the entire treatment period. Twenty-two patients ( $76 \%$ of all patients) showed a secondary decline in 1 or both outcomes. Only 2 patients ( $7 \%$ of all patients) had an ongoing decline in both parameters from the start of treatment (figure 5C). At their last follow-up measurement, 15 patients (52\%) had equal or better 6MWT and/or FVC upright compared to baseline.

There were no obvious differences with respect to their clinical condition at baseline or ancillary investigations (e.g., genotype, antibody peak titers) between the patients with an overall positive response on ERT and those with an ongoing decline.

\section{Safety}

ERT was discontinued in 2 patients ( 1 and 33 months after the start of treatment) for severe infusion-associated reactions and/or very high antibody titers affecting treatment efficacy. ${ }^{25}$ After treatment was stopped, their clinical condition slowly worsened. One other patient stopped 


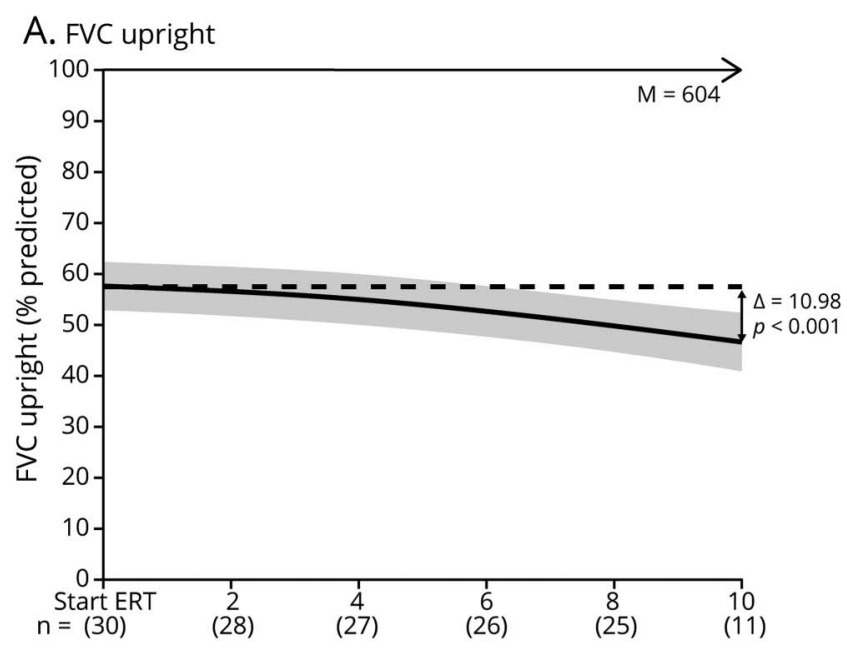

Follow-up duration in years (number of patients)

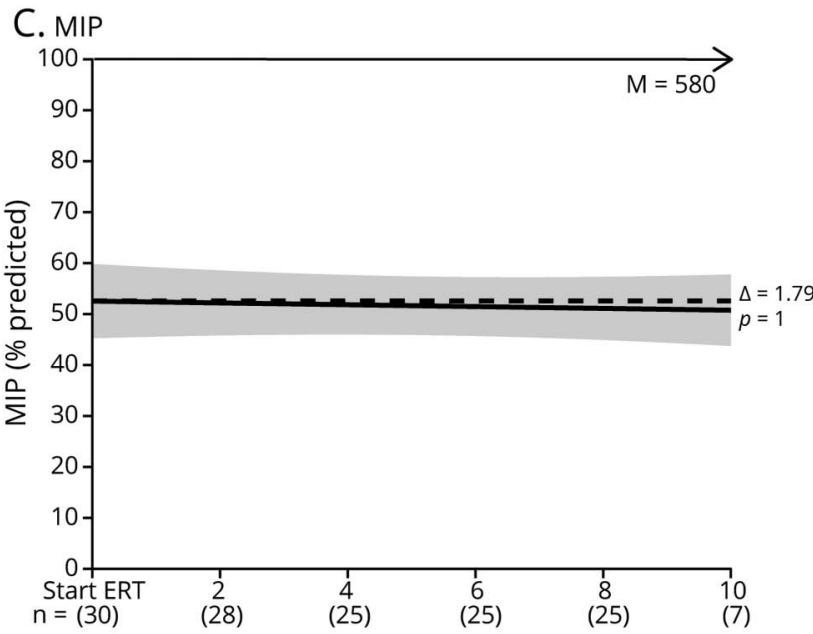

Follow-up duration in years (number of patients)

E. FVC upright (extrapolated natural course)

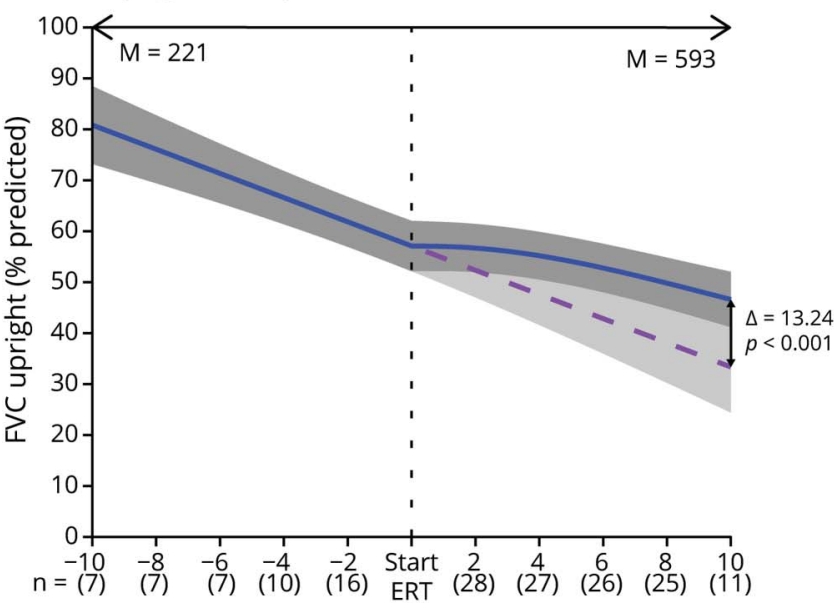

(30)

Follow-up duration in years (number of patients)

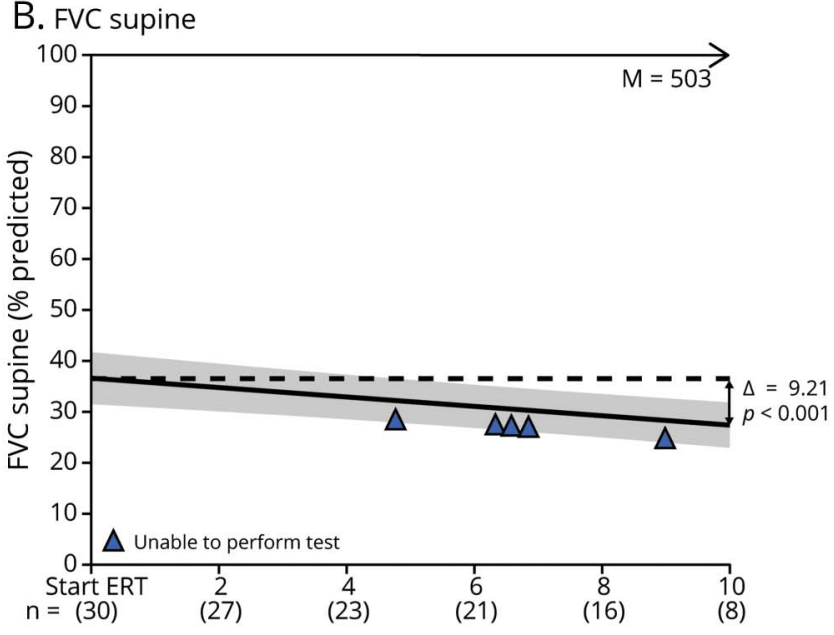

Follow-up duration in years (number of patients)

D. MEP

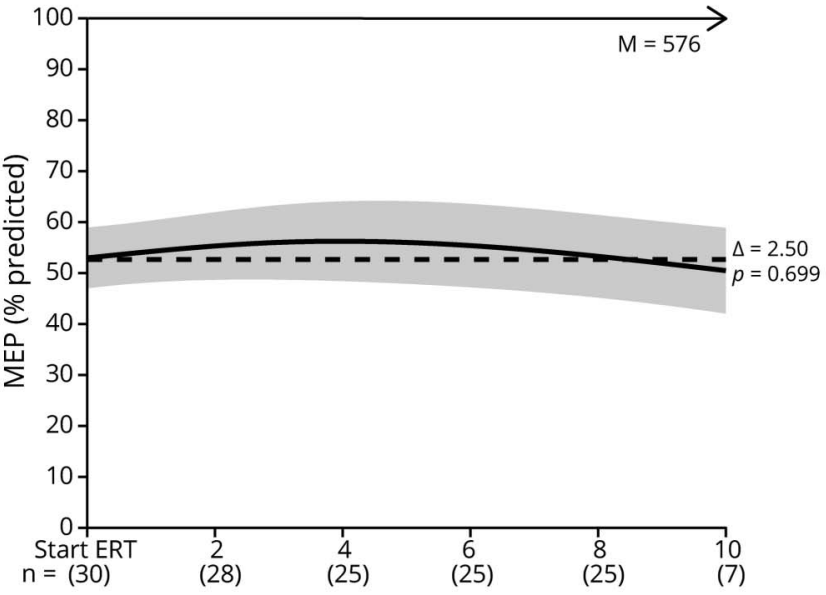

Follow-up duration in years (number of patients)

F. FVC supine (extrapolated natural course)

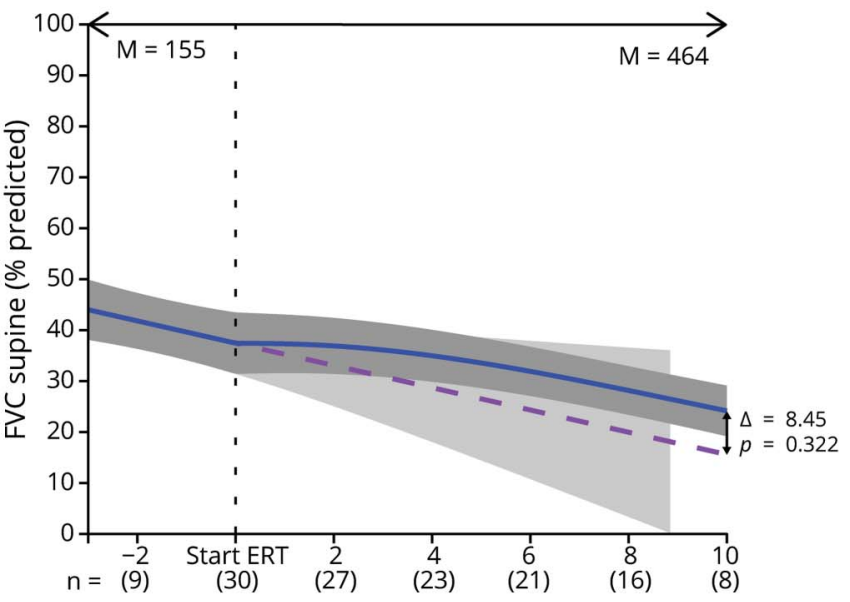

Follow-up duration in years (number of patients)

Disease course at group level after start of enzyme replacement therapy (ERT) for forced vital capacity (FVC) in the upright and supine positions and maximal inspiratory (MIP) and maximal expiratory (MEP) pressures compared to (A-D) baseline or (E and F) the extrapolated natural disease course. Solid lines represent the measured natural course of the disease and/or the course during treatment. Dashed line represents the natural course extrapolated on the basis of natural course data. The $95 \%$ confidence intervals are shown in gray. For FVC supine, the triangles mark the time point from which patients were not able to perform the test due to severe orthopnea or full wheelchair dependency. $\mathrm{M}=$ total number of measurements; $\mathrm{n}=$ number of patients at that time of follow-up. 
A. All individual response patterns

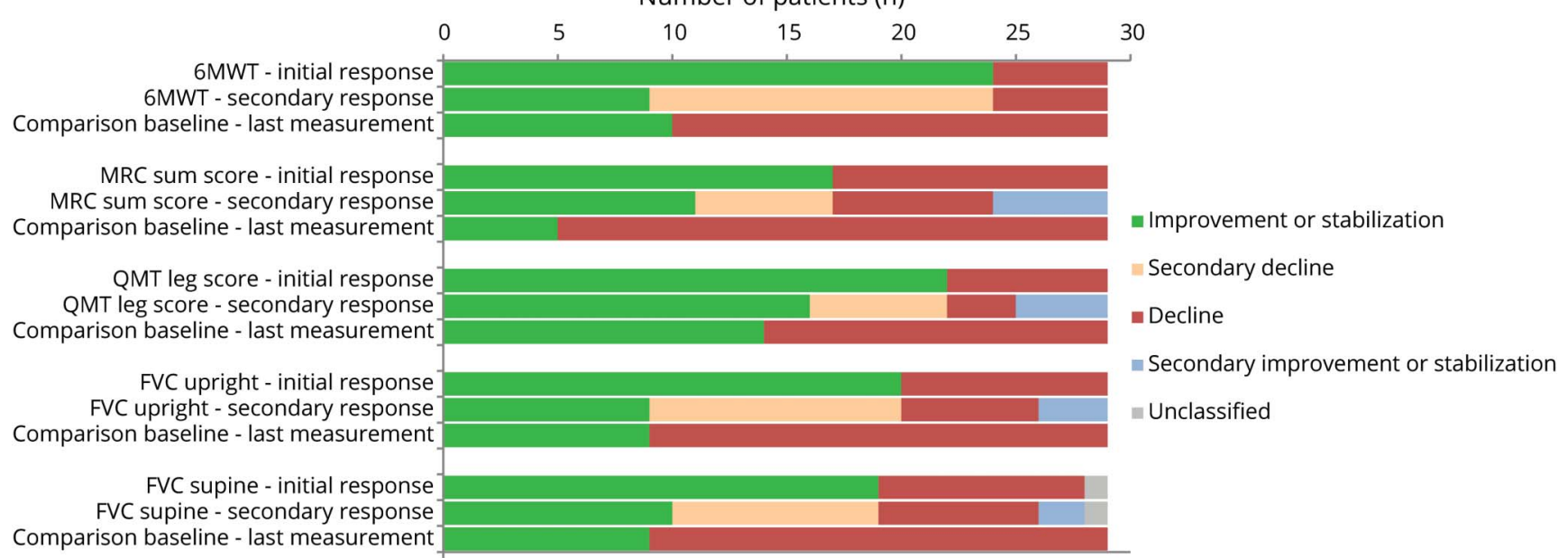

B. Initial response pattern 6MWT and FVC upright

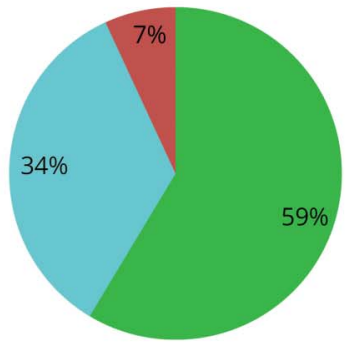

C. Secondary response pattern 6MWT and FVC upright

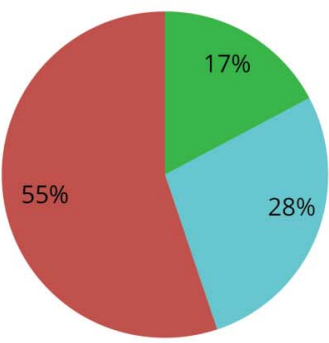

D. Comparison baseline and last outcome 6MWT and FVC upright

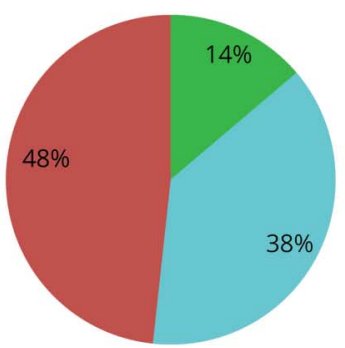

- Improvement or stabilization in both outcomes

- Improvement or stabilization in 6MWT or FVC

- Decline in both outcomes

(A) Initial, secondary, and overall disease course at the individual patient level after the start of enzyme replacement therapy (ERT) for 6-minute walk test (6MWT), Medical Research Council (MRC) sum score, quantitative muscle testing (QMT) leg score, and forced vital capacity (FVC) upright and FVC supine separately. Combined individual patients' response on 6MWT and FVC in upright position, subdivided into (B) initial, (C) secondary, and (D) overall response (D). One patient was excluded from this specific analysis due to the short follow-up time on ERT (1 month). The initial and secondary responses of each individual patient were classified by visual judgment of the disease course (using scatterplots). The overall response was calculated by subtracting the last measurement during ERT from that at the start of ERT.

treatment for personal reasons (after 28 months). This patient became wheelchair and ventilator dependent 3 years after cessation of ERT and died 2 years later at the age of 77 years, probably due to respiratory insufficiency. During the study, a second patient, who was already partially wheelchair and ventilation dependent at the start of ERT, died suddenly at 63 years of age after 10 years of treatment with ERT, possibly due to cardiac arrest (no autopsy performed) (figure 2). Neither of the 2 deaths was considered to be directly treatment related. In 1 patient, treatment with ERT was temporarily discontinued on diagnosis of colon and kidney carcinomas. ERT was reintroduced without side effects after cancer treatment.

\section{Discussion}

In this 10-year prospective study on the effects of ERT, we show that $93 \%$ of adults with Pompe disease benefit from treatment with ERT during $\approx 3$ to 5 years. After that period, many patients experienced a secondary deterioration in walking ability, muscle strength, and/or pulmonary function. For FVC, we could demonstrate that patients' outcomes are better than would have been expected had patients remained untreated, which is to be regarded as a positive effect, taking into account the relentlessly progressive nature of the disease.

Previous studies of up to 5 years of ERT treatment have reported the remarkable change in ERT efficacy during the course of treatment, ${ }^{8,9,26,27}$ yet it was unknown how this would evolve with longer-term follow-up. We now see that, at the group level, the initial positive response to treatment is followed by a slow, seemingly linear, decline. However, looking more closely at the individual patients, we found that 5 patients $(17 \%)$ had a continued positive response on ERT for 10 years, while only 2 patients (7\%) were clear nonresponders (i.e., they had a decline in walking ability and pulmonary function from the start of treatment). Although 
the majority of patients (93\%) initially benefited from ERT, it was difficult to predict the timing in change in responsiveness. In some patients, the good response lasted up to 7 to 8 years, while in others, we observed a secondary decline already after 1 to 2 years. What makes it even more complicated is that the response may be discordant among different outcomes, with some patients demonstrating clear improvement in walking ability while deteriorating in pulmonary function $(n=2,7 \%)$ or vice versa $(n=2,7 \%)$. At the end of follow-up, half of the patients had an improved or stable walking ability, pulmonary function, or both. For the individual analyses per patient, insufficient data on the period before start of ERT were available to compare their course on treatment with their natural disease progression. It could well be that a slight decline while on treatment should also be regarded as a positive effect of ERT (e.g., when the rate of decline while not on ERT is greater than the rate of decline on treatment).

We could not identify any obvious explanation for the differences in individual responsiveness. Two patients did not have the common c.-32-13T>G variant but a potentially more severe genotype. Their disease course on ERT was not significantly different. Some studies have suggested that an earlier start of treatment, while patients are still in a better clinical condition, would lead to better efficacy. ${ }^{9,24}$ In this study, we did not find evidence for a better treatment effect in patients with a shorter disease duration or less severe disease at the start of treatment compared to those with a longer disease duration or more severe disease. However, our conclusion should be interpreted with some caution because of the limited number of patients across subgroups, plus the fact that they all had some level of disease severity to be included in the initial trial. This relatively severe involvement is probably most clearly reflected by the fact that patients' median supine FVC at start of ERT was only $33 \%$ of their predicted normal value, already on the edge of ventilator dependency. This may explain, at least partly, the large increase in the number of patients needing mechanical ventilatory support despite ERT.

As far as we are aware, none of our patients were on a prescribed diet or a specific exercise training program. Because these factors might also influence a patient's response to $\mathrm{ERT}^{28}$ this could be a specific topic of further study.

Another explanation for the differences in individuals' responses to treatment could be the presence of antibodies against the recombinant human acid $\alpha$-glucosidase. In contrast to patients with classic infantile Pompe disease, ${ }^{29-31}$ the relationship between antibodies and clinical outcomes in patients with late-onset disease is not clear. Studies so far, containing data for up to 5 years of ERT treatment, have failed to show a clear correlation between antibody titers and patients' individual response to ERT. $^{22,23}$
In our study, 9 patients (30\%) developed high peak antibody titers $(>1: 31,250)$ during the first 3 years of ERT. Notably, 3 of the 5 patients with a continued positive response to ERT over 10 years on FVC and walking ability had high peak antibody titers. Unfortunately, antibody titers were available only for the first years on treatment; therefore, it cannot be ruled out that they may be of importance in treatment efficacy at a later stage. The role of antibody formation in late-onset Pompe disease should thus be subject of further study.

Factors that can be hypothesized to influence treatmentefficacy are, among others, the content of mannose-6phosphate (M6P) groups on the recombinant enzyme (which is currently low), variability in the number of M6P/ insulin-like growth factor II receptors expressed at the muscle cell surface, the amount of autophagic buildup impeding proper intracellular trafficking and processing of the therapeutic enzyme, and the accessibility of the enzyme to stored glycogen within the muscle cells. ${ }^{32-35}$ This is why nextgeneration therapies are directed at rescuing the disrupted lysosomal glycogen degradation pathway through improved targeting of the $\mathrm{M} 6 \mathrm{P} /$ insulin-like growth factor II receptor, responsible for uptake of the infused enzyme and mediating transport to the lysosomes. In addition, we have shown recently that in infants higher dosing $(40 \mathrm{mg} / \mathrm{kg} / \mathrm{wk})$ resulted in better ventilator-free survival and motor outcome. ${ }^{36}$ For obvious reasons (i.e., the very costly treatment), higher dosing strategies have never been applied in adult patients, but insufficient dosing might explain part of the deterioration we observe.

When evaluating therapeutic interventions, one should always search for outcome measures that best capture clinical meaningful changes. In this context, it was notable to see that, during the 10-year follow-up, 8 patients were not able to perform the 6MWT anymore either because they had become fully wheelchair dependent or because the evaluator thought the risk of falling was too high. In addition, 5 patients were no longer able to endure the supine position for FVC testing. For these very severely affected patients, but also for patients with still minimal weakness, additional measurements should be considered to evaluate their long-term treatment response. For patients who are still able to walk short distances, gait analysis may be of additional value. Here, velocity, duration of stance phase, and step and stride length can be evaluated, as well as when walking devices are used. ${ }^{37-39}$ For a more detailed evaluation of pulmonary function, spirometrycontrolled MRI or ultrasonography of the diaphragm may be appropriate. ${ }^{40-42}$ In addition, evaluation of muscle function could possibly be more reliably evaluated with patientreported outcome measures, reporting activities in daily life. ${ }^{43,44}$

In 2017, European consensus guidelines were published on the use of ERT in adult patients with Pompe disease. ${ }^{45}$ Within this consensus statement, recommendations on when to stop 
ERT treatment are posed. One of these recommendations is to reconsider whether ERT should be continued if skeletal muscle function or respiratory function has not stabilized or improved in the first 2 years after the start of treatment. Our study showed that $93 \%$ of all patients had initial benefit of ERT. Two patients (7\%) deteriorated from the beginning, despite ERT; in these patients, we are considering the cessation of ERT.

Our study shows that there is large interindividual variation not only in response patterns but also in duration of treatment efficacy and that the treatment effects may be discordant across multiple outcomes. Because we do not yet fully understand the factors underlying the great variability in treatment response, predicting before treatment initiation who will do well or not is currently not possible. Although $>90 \%$ of patients benefit from ERT for the first 3 to 5 years, the observed secondary decline, suggesting diminished therapeutic efficacy over time, raises concerns and stresses the need for next-generation therapies.

\section{Disclosure}

L. Harlaar, J. Hogrel, B. Perniconi, M. Kruijshaar, D. Rizopoulos, N. Taouagh, A. Canal, E. Brusse, and P. van Doorn reports no disclosures relevant to the manuscript. A. van der Ploeg received funding for research, clinical trials and as an advisor from various industries working on ERT or nextgeneration therapies in the field of Pompe disease, other lysosomal storage diseases, and neuromuscular disorders under agreements with Erasmus MC University Medical Center and the relevant industry. P. Laforêt received funding for research and as an advisor or speaker from Sanofi-Genzyme and Spark Therapeutics. N. van der Beek received funding for research and as advisor from various industries working on ERT or next-generation therapies in the field of Pompe disease under agreements with Erasmus MC University Medical Center and the relevant industry. Go to Neurology.org/N for full disclosures.

\section{Study funding}

Study funded by the Netherlands Organization for Health Research and Development (projects 152001005, 8083600-98-13007, and 05-09-2007); the Prinses Beatrix Spierfonds (projects OP07-08 and W.OR15-10); the Sophia Children's Hospital Foundation (projects 687 and S17-32); Ministry of Economic Affairs under TKIAllowance under the TKI-programme Life Sciences \& Health (project LSHM16008); Myology Institute; INSERM; and Sanofi-Genzyme. Dr. van der Beek received a postdoctoral fellowship from the Prinses Beatrix Spierfonds (W.F16-03).

\section{Publication history}

Received by Neurology February 15, 2019. Accepted in final form May 29, 2019.

\section{Appendix Authors}

\begin{tabular}{|c|c|c|c|}
\hline Name & Location & Role & Contribution \\
\hline $\begin{array}{l}\text { Laurike } \\
\text { Harlaar, MD }\end{array}$ & $\begin{array}{l}\text { Department of } \\
\text { Neurology, Center for } \\
\text { Lysosomal and } \\
\text { Metabolic Diseases, } \\
\text { Erasmus MC, } \\
\text { University Medical } \\
\text { Center Rotterdam, } \\
\text { Rotterdam, the } \\
\text { Netherlands }\end{array}$ & Author & $\begin{array}{l}\text { Study concept and } \\
\text { design, acquisition } \\
\text { of data, analysis and } \\
\text { interpretation of data, } \\
\text { statistical analysis, } \\
\text { drafting of } \\
\text { manuscript }\end{array}$ \\
\hline $\begin{array}{l}\text { Jean-Yves } \\
\text { Hogrel, PhD }\end{array}$ & $\begin{array}{l}\text { Institute of Myology, } \\
\text { Pitié-Salpêtrière } \\
\text { Hospital, Paris, } \\
\text { France }\end{array}$ & Author & $\begin{array}{l}\text { Acquisition of data, } \\
\text { analysis and } \\
\text { interpretation of data, } \\
\text { study supervision, } \\
\text { critical revision of } \\
\text { manuscript for } \\
\text { intellectual } \\
\text { content }\end{array}$ \\
\hline
\end{tabular}

Barbara Institute of Myology, Author Acquisition of data,

Perniconi, Pitié-Salpêtrière $\quad$ Author Acquisition of das and

CRA Hospital, Paris, interpretation of France data, critical revision of manuscript for intellectual

content

\begin{tabular}{|c|c|c|c|}
\hline $\begin{array}{l}\text { Michelle E. } \\
\text { Kruijshaar, } \\
\text { PhD }\end{array}$ & $\begin{array}{l}\text { Department of } \\
\text { Pediatrics, Center for } \\
\text { Lysosomal and } \\
\text { Metabolic Diseases, } \\
\text { Erasmus MC, } \\
\text { University Medical } \\
\text { Center Rotterdam, } \\
\text { Rotterdam, the } \\
\text { Netherlands }\end{array}$ & Author & $\begin{array}{l}\text { Analysis and } \\
\text { interpretation of data, } \\
\text { statistical analysis, } \\
\text { critical revision of } \\
\text { manuscript for } \\
\text { intellectual content }\end{array}$ \\
\hline $\begin{array}{l}\text { Dimitris } \\
\text { Rizopoulos, } \\
\text { PhD }\end{array}$ & $\begin{array}{l}\text { Department of } \\
\text { Biostatistics, Erasmus } \\
\text { MC, University } \\
\text { Medical Center } \\
\text { Rotterdam, } \\
\text { Rotterdam, the } \\
\text { Netherlands }\end{array}$ & Author & $\begin{array}{l}\text { Analysis and } \\
\text { interpretation of data, } \\
\text { statistical analysis, } \\
\text { critical revision of } \\
\text { manuscript for } \\
\text { intellectual content }\end{array}$ \\
\hline $\begin{array}{l}\text { Nadjib } \\
\text { Taouagh, } \\
\text { CRA }\end{array}$ & $\begin{array}{l}\text { Institute of Myology, } \\
\text { Pitié-Salpêtrière } \\
\text { Hospital, Paris, } \\
\text { France }\end{array}$ & Author & $\begin{array}{l}\text { Acquisition of data, } \\
\text { critical revision of } \\
\text { manuscript for } \\
\text { intellectual content }\end{array}$ \\
\hline $\begin{array}{l}\text { Aurélie } \\
\text { Canal, PT }\end{array}$ & $\begin{array}{l}\text { Institute of Myology, } \\
\text { Pitié-Salpêtrière } \\
\text { Hospital, Paris, } \\
\text { France }\end{array}$ & Author & $\begin{array}{l}\text { Acquisition of data, } \\
\text { critical revision of } \\
\text { manuscript for } \\
\text { intellectual } \\
\text { content }\end{array}$ \\
\hline $\begin{array}{l}\text { Esther } \\
\text { Brusse, MD, } \\
\text { PhD }\end{array}$ & $\begin{array}{l}\text { Department of } \\
\text { Neurology, Center for } \\
\text { Lysosomal and } \\
\text { Metabolic Diseases, } \\
\text { Erasmus MC, } \\
\text { University Medical } \\
\text { Center Rotterdam, } \\
\text { Rotterdam, the } \\
\text { Netherlands }\end{array}$ & Author & $\begin{array}{l}\text { Analysis and } \\
\text { interpretation of data, } \\
\text { study supervision, } \\
\text { critical revision of } \\
\text { manuscript for } \\
\text { intellectual content }\end{array}$ \\
\hline $\begin{array}{l}\text { Pieter A. } \\
\text { van Doorn, } \\
\text { MD, PhD }\end{array}$ & $\begin{array}{l}\text { Department of } \\
\text { Neurology, Center for } \\
\text { Lysosomal and } \\
\text { Metabolic Diseases, } \\
\text { Erasmus MC, } \\
\text { University Medical } \\
\text { Center Rotterdam, } \\
\text { Rotterdam, the } \\
\text { Netherlands }\end{array}$ & Author & $\begin{array}{l}\text { Study concept and } \\
\text { design, analysis and } \\
\text { interpretation of data, } \\
\text { study supervision, } \\
\text { critical revision of } \\
\text { manuscript for } \\
\text { intellectual content }\end{array}$ \\
\hline
\end{tabular}


Appendix (continued)

\begin{tabular}{|c|c|c|c|}
\hline Name & Location & Role & Contribution \\
\hline $\begin{array}{l}\text { Ans T. van } \\
\text { der Ploeg, } \\
\text { MD, PhD }\end{array}$ & $\begin{array}{l}\text { Department of } \\
\text { Pediatrics, Center for } \\
\text { Lysosomal and } \\
\text { Metabolic Diseases, } \\
\text { Erasmus MC, } \\
\text { University Medical } \\
\text { Center Rotterdam, } \\
\text { Rotterdam, the } \\
\text { Netherlands }\end{array}$ & Author & $\begin{array}{l}\text { Study concept and } \\
\text { design, analysis and } \\
\text { interpretation of data, } \\
\text { study supervision, } \\
\text { critical revision of } \\
\text { manuscript for } \\
\text { intellectual content }\end{array}$ \\
\hline $\begin{array}{l}\text { Pascal } \\
\text { Laforêt, } \\
\text { MD, PhD }\end{array}$ & $\begin{array}{l}\text { Neurology } \\
\text { Department, Nord/ } \\
\text { Est/lle de France } \\
\text { Neuromuscular } \\
\text { Center, Raymond } \\
\text { Poincaré Teaching } \\
\text { Hospital, AP-HP } \\
\text { Garches, France; }\end{array}$ & Author & $\begin{array}{l}\text { Study concept and } \\
\text { design, acquisition of } \\
\text { data, analysis and } \\
\text { interpretation of data, } \\
\text { study supervision, } \\
\text { critical revision of } \\
\text { manuscript for } \\
\text { intellectual content }\end{array}$ \\
\hline
\end{tabular}

INSERM U1179, END-

ICAP, Université

Versailles Saint-

Quentin-en-Yvelines,

Montigny-le-

Bretonneux, France

\begin{tabular}{|c|c|c|c|}
\hline $\begin{array}{l}\text { Nadine } \\
\text { A.M.E. van } \\
\text { der Beek, } \\
\text { MD, PhD }\end{array}$ & $\begin{array}{l}\text { Department of } \\
\text { Neurology, Center for } \\
\text { Lysosomal and } \\
\text { Metabolic Diseases, } \\
\text { Erasmus MC, } \\
\text { University Medical } \\
\text { Center Rotterdam, } \\
\text { Rotterdam, the } \\
\text { Netherlands }\end{array}$ & Author & $\begin{array}{l}\text { Study concept and } \\
\text { design, acquisition of } \\
\text { data, analysis and } \\
\text { interpretation of data, } \\
\text { statistical analysis, } \\
\text { study supervision, } \\
\text { critical revision of } \\
\text { manuscript for } \\
\text { intellectual content }\end{array}$ \\
\hline
\end{tabular}

\section{References}

1. van der Ploeg AT, Reuser AJ. Pompe's disease. Lancet 2008;372:1342-1353.

2. Reuser AJJ, Hirschhorn R, Kroos MA. Pompe disease: glycogen storage disease type II, acid $\alpha$-glucosidase (acid maltase) deficiency. In: Valle D, Beaudet AL, Vogelstein B, et al, editors. The Online Metabolic and Molecular Bases of Inherited Disease. New York: McGraw-Hill; 2018;part 16, chapter 135.

3. van der Beek NA, de Vries JM, Hagemans ML, et al. Clinical features and predictor for disease natural progression in adults with Pompe disease: a nationwide prospective observational study. Orphanet J Rare Dis 2012;7:88.

4. van der Beek NA, Hagemans ML, Reuser AJ, et al. Rate of disease progression during long-term follow-up of patients with late-onset Pompe disease. Neuromuscul Disord 2009;19:113-117.

5. Anderson LJ, Henley W, Wyatt KM, et al. Effectiveness of enzyme replacement therapy in adults with late-onset Pompe disease: results from the NCS-LSD cohort study. J Inherit Metab Dis 2014;37:945-952.

6. Angelini C, Semplicini C, Ravaglia S, et al. Observational clinical study in juvenileadult glycogenosis type 2 patients undergoing enzyme replacement therapy for up to 4 years. J Neurol 2012;259:952-958.

7. Güngör D, Kruijshaar ME, Plug I, et al. Impact of enzyme replacement therapy on survival in adults with Pompe disease: results from a prospective international observational study. Orphanet J Rare Dis 2013;8:49.

8. Kuperus E, Kruijshaar ME, Wens SCA, et al. Long-term benefit of enzyme replacement therapy in Pompe disease: a 5-year prospective study. Neurology 2017;89: 2365-2373.

9. Stepien KM, Hendriksz CJ, Roberts M, Sharma R. Observational clinical study of 22 adult-onset Pompe disease patients undergoing enzyme replacement therapy over 5years. Mol Genet Metab 2016;117:413-418.

10. Strothotte S, Strigl-Pill N, Grunert B, et al. Enzyme replacement therapy with alglucosidase alfa in 44 patients with late-onset glycogen storage disease type 2: 12 month results of an observational clinical trial. J Neurol 2010;257:91-97.

11. van der Ploeg AT, Clemens PR, Corzo D, et al. A randomized study of alglucosidase alfa in late-onset Pompe's disease. N Engl J Med 2010;362:1396-1406.

12. van der Ploeg AT, Barohn R, Carlson L, et al. Open-label extension study following the Late-Onset Treatment Study (LOTS) of alglucosidase alfa. Mol Genet Metab 2012;107:456-461.

13. Enright PL, Sherrill DL. Reference equations for the six-minute walk in healthy adults. Am J Respir Crit Care Med 1998;158:1384-1387.

14. Medical Research Council. AIDS to Examination of the Peripheral Nervous System. London: Her Majesty's Stationary Office; 1976. Memorandum No. 45.
15. Florence JM, Pandya S, King WM, et al. Clinical trials in Duchenne dystrophy: standardization and reliability of evaluation procedures. Phys Ther 1984;64:41-45.

16. Muscular weakness assessment: use of normal isometric strength data: the National Isometric Muscle Strength (NIMS) Database Consortium. Arch Phys Med Rehabil 1996;77:1251-1255.

17. Hogrel JY, Payan CA, Ollivier G, et al. Development of a French isometric strength normative database for adults using quantitative muscle testing. Arch Phys Med Rehabil 2007;88:1289-1297.

18. American Thoracic Society/European Respiratory Society. ATS/ERS statement on respiratory muscle testing. Am J Respir Crit Care Med 2002;166:518-624.

19. Miller MR, Hankinson J, Brusasco V, et al. Standardisation of spirometry. Eur Respir J 2005;26:319-338.

20. Quanjer PH, Stanojevic S, Cole TJ, et al. Multi-ethnic reference values for spirometry for the 3-95-yr age range: the global lung function 2012 equations. Eur Respir J 2012; 40:1324-1343.

21. Wilson SH, Cooke NT, Edwards RH, Spiro SG. Predicted normal values for maximal respiratory pressures in Caucasian adults and children. Thorax 1984;39:535-538.

22. de Vries JM, Kuperus E, Hoogeveen-Westerveld M, et al. Pompe disease in adulthood: effects of antibody formation on enzyme replacement therapy. Genet Med 2017;19:90-97.

23. Masat E, Laforet $\mathrm{P}, \mathrm{De}$ Antonio $\mathrm{M}$, et al. Long-term exposure to myozyme results in a decrease of anti-drug antibodies in late-onset Pompe disease patients. Sci Rep 2016; 6:36182.

24. de Vries JM, van der Beek NA, Hop WC, et al. Effect of enzyme therapy and prognostic factors in 69 adults with Pompe disease: an open-label single-center study. Orphanet J Rare Dis 2012;7:73.

25. de Vries JM, van der Beek NA, Kroos MA, et al. High antibody titer in an adult with Pompe disease affects treatment with alglucosidase alfa. Mol Genet Metab 2010;101: 338-345

26. Montagnese F, Barca E, Musumeci O, et al. Clinical and molecular aspects of 30 patients with late-onset Pompe disease (LOPD): unusual features and response to treatment. J Neurol 2015;262:968-978.

27. Andreassen CS, Schlutter JM, Vissing J, Andersen H. Effect of enzyme replacement therapy on isokinetic strength for all major muscle groups in four patients with Pompe disease: a long-term follow-up. Mol Genet Metab 2014;112:40-43.

28. van den Berg LE, Favejee MM, Wens SC, et al. Safety and efficacy of exercise training in adults with Pompe disease: evaluation of endurance, muscle strength and core stability before and after a 12 week training program. Orphanet J Rare Dis 2015;10:87.

29. Kishnani PS, Goldenberg PC, DeArmey SL, et al. Cross-reactive immunologic material status affects treatment outcomes in Pompe disease infants. Mol Genet Metab 2010;99:26-33.

30. van Gelder CM, Hoogeveen-Westerveld M, Kroos MA, Plug I, van der Ploeg AT, Reuser AJ. Enzyme therapy and immune response in relation to CRIM status: the Dutch experience in classic infantile Pompe disease. J Inherit Metab Dis 2015;38: 305-314

31. Poelman E, Hoogeveen-Westerveld M, Kroos-de Haan MA, et al. High sustained antibody titers in patients with classic infantile Pompe disease following immunomodulation at start of enzyme replacement therapy. J Pediatr 2018;195:236-243.e3.

32. van der Ploeg AT, Kroos MA, Willemsen R, Brons NH, Reuser AJ. Intravenous administration of phosphorylated acid alpha-glucosidase leads to uptake of enzyme in heart and skeletal muscle of mice. J Clin Invest 1991;87:513-518.

33. Raben N, Danon M, Gilbert AL, et al. Enzyme replacement therapy in the mouse model of Pompe disease. Mol Genet Metab 2003;80:159-169.

34. Thurberg BL, Lynch Maloney C, Vaccaro C, et al. Characterization of pre- and posttreatment pathology after enzyme replacement therapy for Pompe disease. Lab Invest 2006;86:1208-1220

35. Raben N, Roberts A, Plotz PH. Role of autophagy in the pathogenesis of Pompe disease. Acta Myol 2007;26:45-48.

36. van Gelder CM, Poelman E, Plug I, et al. Effects of a higher dose of alglucosidase alfa on ventilator-free survival and motor outcome in classic infantile Pompe disease: an open-label single-center study. J Inherit Metab Dis 2016;39:383-390.

37. McIntosh PT, Case LE, Chan JM, Austin SL, Kishnani P. Characterization of gait in late onset Pompe disease. Mol Genet Metab 2015;116:152-156.

38. Hanewinckel R, Drenthen J, Verlinden VJA, et al. Polyneuropathy relates to impairment in daily activities, worse gait, and fall-related injuries. Neurology 2017;89:76-83.

39. Goudriaan M, Van den Hauwe M, Dekeerle J, et al. Gait deviations in Duchenne muscular dystrophy, part 1: a systematic review. Gait Posture 2018;62:247-261.

40. Wens SC, Ciet P, Perez-Rovira A, et al. Lung MRI and impairment of diaphragmatic function in Pompe disease. BMC Pulm Med 2015;15:54.

41. Gaeta M, Musumeci O, Mondello S, et al. Clinical and pathophysiological clues of respiratory dysfunction in late-onset Pompe disease: new insights from a comparative study by MRI and respiratory function assessment. Neuromuscul Disord 2015;25: 852-858.

42. Sarwal A, Walker FO, Cartwright MS. Neuromuscular ultrasound for evaluation of the diaphragm. Muscle Nerve 2013;47:319-329.

43. van der Beek NA, Hagemans ML, van der Ploeg AT, van Doorn PA, Merkies IS. The Rasch-Built Pompe-Specific Activity (R-PAct) scale. Neuromuscul Disord 2013;23: 256-264.

44. Vandervelde L, Van den Bergh PY, Goemans N, Thonnard JL. Activity limitations in patients with neuromuscular disorders: a responsiveness study of the ACTIVLIM questionnaire. Neuromuscul Disord 2009;19:99-103.

45. van der Ploeg AT, Kruijshaar ME, Toscano A, et al. European consensus for starting and stopping enzyme replacement therapy in adult patients with Pompe disease: a 10year experience. Eur J Neurol 2017;24:768-e31. 


\section{Neurology}

\section{Large variation in effects during 10 years of enzyme therapy in adults with Pompe disease}

Laurike Harlaar, Jean-Yves Hogrel, Barbara Perniconi, et al.

Neurology 2019;93;e1756-e1767 Published Online before print October 16, 2019

DOI 10.1212/WNL.0000000000008441

This information is current as of October 16, 2019

\section{Updated Information \& Services}

References

Citations

Subspecialty Collections

Permissions \& Licensing

Reprints including high resolution figures, can be found at: http://n.neurology.org/content/93/19/e1756.full

This article cites 43 articles, 6 of which you can access for free at: http://n.neurology.org/content/93/19/e1756.full\#ref-list-1

This article has been cited by 3 HighWire-hosted articles: http://n.neurology.org/content/93/19/e1756.full\#\#otherarticles

This article, along with others on similar topics, appears in the following collection(s):

All Clinical Neurology

http://n.neurology.org/cgi/collection/all_clinical_neurology

All Neuromuscular Disease

http://n.neurology.org/cgi/collection/all_neuromuscular_disease

Clinical trials Observational study (Cohort, Case control)

http://n.neurology.org/cgi/collection/clinical_trials_observational_stud y_cohort_case_control

Glycogenoses

http://n.neurology.org/cgi/collection/glycogenoses

Metabolic disease (inherited)

http://n.neurology.org/cgi/collection/metabolic_disease_inherited

Information about reproducing this article in parts (figures,tables) or in its entirety can be found online at:

http://www.neurology.org/about/about_the_journal\#permissions

Information about ordering reprints can be found online:

http://n.neurology.org/subscribers/advertise

Neurology ${ }^{\circledR}$ is the official journal of the American Academy of Neurology. Published continuously since 1951, it is now a weekly with 48 issues per year. Copyright Copyright ( 2019 The Author(s). Published by Wolters Kluwer Health, Inc. on behalf of the American Academy of Neurology.. All rights reserved. Print ISSN: 0028-3878. Online ISSN: 1526-632X.

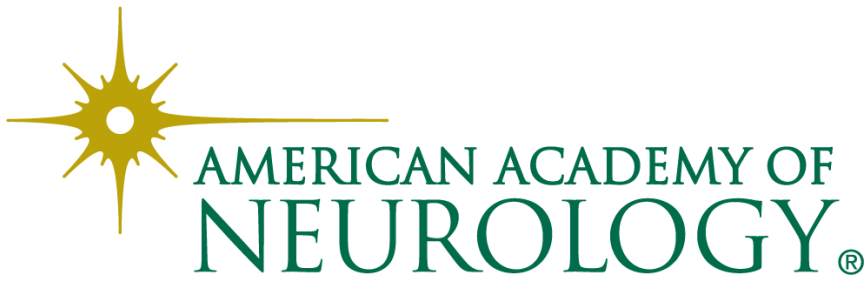

